\title{
The Arc Elasticity of Demand: A Note and Comment
}

\section{Michael B. Vaughan}

In this journal, Seldon (1986) recently criticized the arc elasticity concept as it is commonly taught in the principles course. In doing so, he resurrected the Lerner (1933a) measure of elasticity, which is based upon the lower values of price and quantity in a price change rather than the average values used in the traditional measure (i.e., the midpoint formula). Seldon argued that the Lerner measure is appropriate for the pedagogy of the principles course because it is more conducive to a graphical interpretation of the revenue impacts accompanying price changes.

In this article, I further examine the suitability of the traditional arc elasticity measure for the principles curriculum. I demonstrate that the midpoint measure is subject to an inherent shortcoming because it invariably tends to approach one as price changes become large. For this reason, the arc elasticity measure may indicate no change in total revenue when, in fact, total revenue increases or decreases. The analysis strengthens the argument for altering the treatment of elasticity in the principles course. Point elasticity of demand is examined as an alternative to the midpoint measure in the principles course.

\section{THE BIAS OF THE ARC ELASTICITY MEASURE}

In his classic examination of the arc elasticity of demand, R. G. D. Allen (1933) argued that any such measure of elasticity should satisfy the following conditions: (1) be symmetrical with respect to the two prices and two quantities that define the arc, (2) not depend upon the units of measurement of price and quantity, and (3) yield a value of unity whenever the total revenues at two price-quantity combinations are equal. Allen advocated the use of the midpoint arc elasticity formula, which became and remains the accepted measure. There is no question that the traditional midpoint measure of arc elasticity satisfies the three properties set forth by Allen. However, Allen's third criterion, regarding the relationship between elasticity and total revenue, implies an additional property that any acceptable measure of arc elasticity must also satisfy. Specifically, a measure of

Michael B. Vaughan is an associate professor of economics and the Willard L. Eccles Fellow at Weber State College. He thanks Hirchel Kasper, W. James Smith, and an anonymous referee for their comments on an earlier draft of this paper. 
elasticity should not yield a value of unity when the total revenues at two price-quantity combinations are not equal. The traditional arc measure of elasticity fails to satisfy this standard.

To see how arc elasticity distorts the magnitude and direction of any revenue change, consider a constant elasticity demand schedule given by $Q=P^{n}$, where $\eta$ is price elasticity at any point along the demand curve. The arc elasticity of demand, denoted by $\mathrm{A} \epsilon$, along an arc defined by pricequantity combinations $P_{x} Q_{x}$ and $P_{y} Q_{y}$, may be written as

$$
\mathrm{A} \epsilon=\left[P_{x}^{\eta}-P_{y}^{\eta}\right] /\left[P_{x}^{\eta}+P_{y}^{\eta}\right] \div\left[P_{x}-P_{y}\right] /\left[P_{x}+P_{y}\right] .
$$

With $P_{y}$ held constant, an inspection of equation(1) reveals that the value of A $\epsilon$ will approach negative one as the value of $P_{x}$ approaches infinity, that is,

$$
\lim _{P_{x} \rightarrow \infty} \mathrm{A} \epsilon=-1 .
$$

The value of A $\epsilon$ will approach $\eta$ as $P_{x}$ approaches $P_{y}$, that is,

$$
\lim A \epsilon=\eta \text {. }
$$$$
P_{x} \rightarrow P_{y}
$$

Further, A $\epsilon$ will equal $\eta$ only when $\eta=-1$. For any noninfinitesimal change in price, $|\mathrm{A} \epsilon|<|\eta|$ when $|\eta|>1$, and $|\mathrm{A} \epsilon|>\eta$ when $|\eta|<1$. Figure 1 illustrates this relationship between elasticity and $\boldsymbol{P}_{\boldsymbol{x}}$.

It is generally recognized that the impact of any percentage increase in price will result in a percentage change in total revenue equaling $1+\eta$. An increase in price will result in an increase in revenue when $|\eta|<1$, a decrease in revenue when $|\eta|>1$, and no change in revenue when $|\eta|=1$. For any noninfinitesimal change in price, the arc elasticity measure will not accurately reflect the magnitude of the change in revenue corresponding to a change in price. Given absolute values of $\eta$ greater than unity, the arc elasticity measure will consistently underestimate the magnitude of the increase in revenue corresponding to a decrease in price. Conversely, when the absolute value of $\eta$ is less than one, arc elasticity will overestimate the impact of a change in price upon total revenue. The greater the departure of $\eta$ from unity, the greater the value of this distortion. Importantly, then, arc elasticity, which was intended to address "large" changes in price, is subject to greater and ever-increasing distortion the greater the change in price considered. ${ }^{1}$ As $P_{x}$ approaches infinity, the arc elasticity measure will suggest no change in revenue regardless of the actual value of $\nu$.

This distortion is not limited to constant elasticity functions. Given any demand function $Q(p)$,

$$
\begin{aligned}
\lim _{P_{x} \rightarrow \infty} \mathrm{A} \epsilon=\left[Q_{x}\left(p_{x}\right)-Q_{y}\left(p_{y}\right)\right] / & {\left[Q_{x}\left(p_{x}\right)+Q_{y}\left(p_{y}\right)\right] } \\
& \div\left[P_{x}-P_{y}\right] /\left[P_{x}+P_{y}\right]=|1| .
\end{aligned}
$$

Thus, for two points along a demand schedule, the arc elasticity measure will produce a distorted elasticity estimate for noninfinitesimal price changes and tend to equal unity as the change in price approaches infinity. ${ }^{2}$ 


\section{FIGURE 1}

Relationship between Elasticity and $\boldsymbol{P}_{\boldsymbol{x}}$

Value of Arc

Elasticity

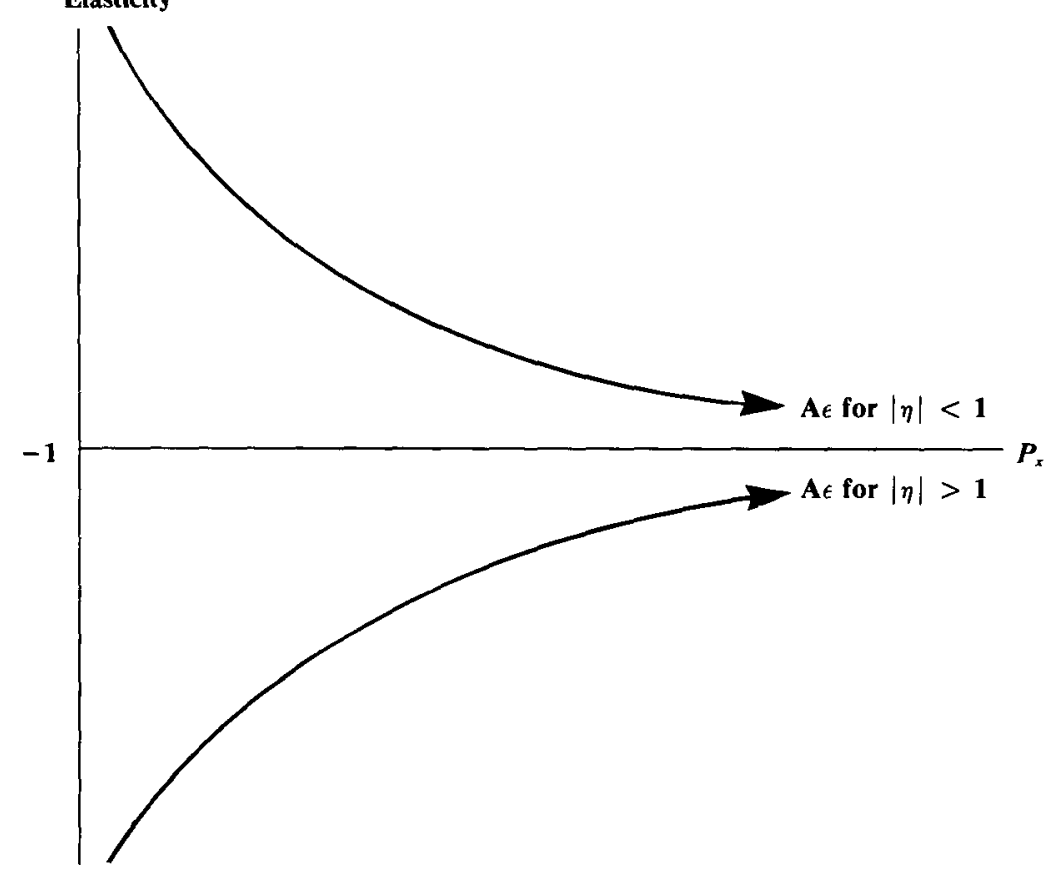

\section{ELASTICITY AND THE PRINCIPLES COURSE}

This proof suggests that the arc elasticity measure is inappropriate for some theoretical and applied work. It also calls into question the role of arc elasticity in the principles course. As Seldon noted, Gould and Ferguson (1980), Machlup (1952), and Lerner (1933a) have discussed the measure, using the lesser values of price and quantity for calculating elasticity. In light of the present analysis, the possibility of replacing the arc concept in the principles course merits attention.

The coverage of price elasticity of demand in the principles course serves a number of pedagogical objectives. Students come to understand the difference between relative and absolute rates of change. They are also made aware of the fact that buyers respond with different intensities to given percentage changes in prices. In addition, some instructors acquaint students with the interrelationships of profits, revenue, and elasticity. Each of these objectives may also be served with the traditional midpoint elasticity measure, but it is subject to the aforementioned distortion. Similarly, the Lerner measure may be used as well, but it sacrifices the symmetry of the 
midpoint formula. A third alternative is the familiar point elasticity concept.

The point measure acquaints students with all of the aforementioned cognitive concepts associated with elasticity. The point measure is simpler to calculate than any of the arc measures. This is critical for weaker principles students who never seem to fully grasp the information conveyed by elasticity because they misdirect the bulk of their efforts to the memorization of the midpoint formula, which they find difficult. Their difficulty is understandable, for the practice in calculating growth rates, inflation rates, and percentage changes in general is to use the original value as the base. Although the symmetry of the midpoint measure results in the same elasticity value for price increases and decreases along an arc, the point measure provides a specific value for elasticity at a particular price. For this reason, the point measure teaches students that different starting points yield different percentage changes for any given absolute change. When these factors are considered, the case for adopting point elasticity as the standard concept for the principles course is strong.

The reluctance to use the point measure in the principles course probably stems from the belief that calculus must be used to calculate point elasticity. This view is unwarranted. Although calculus must be used to obtain the slope of a nonlinear demand function at a point, the slope of a linear function at a point is simply the ratio of rise to run. For a demand schedule of the form $Q=a-b P$, the slope of demand at a point equals the slope of demand along a discrete arc, (i.e., $\partial Q / \partial P=\left[Q_{1}-Q_{2}\right] /\left[P_{2}-P_{1}\right]=-b$ ). If numerical calculations are restricted to linear demand functions, students with no background in calculus can calculate point elasticity. This should not disrupt the coverage of the elasticity concept because all of the familiar revenue relationships can be derived from linear schedules. In fact, multiplicative and constant elasticity demand schedules are not normally covered at the principles level. ${ }^{3}$

Perhaps the most significant obstacle to removing the arc elasticity concept from the principles course is inertia. Arc elasticity is embedded in hundreds of principles textbooks and thousands of lecture notes. In this paper, however, I have demonstrated that the concept of arc elasticity is fundamentally flawed. Although the costs of altering the principles course are certainly significant, this may be one instance where the benefits of a curriculum change outweigh the costs.

\section{NOTES}

1. The term large is used here in the sense of calculus. This note demonstrates that the midpoint formula will produce a distorted estimate of elasticity whenever the change in price is not infinitesimally small. The severity of this bias depends upon the particular application.

2. Bradley (1985) defines the arc elasticity of demand as "the average elasticity between two prices. . . "Several other contemporary textbook authors present essentially identical definitions. That this definition is incorrect is clearly demonstrated when one considers the limit of equations (1) and (2).

3. The general discussion of the concept need not be limited to linear demand schedules. Only specific elasticity calculations need to employ linear data. 


\section{REFERENCES}

Allen, R. G. D. 1933-1934. The concept of arc elasticity of demand: I. Review of Economic Studies 1 (3): 226-29.

Bradley, M. 1985. Microeconomics. 2d ed. Glenview: Scott, Foresman and Company.

Gould, J. P., and C. E. Ferguson. 1980. Microeconomic theory. 5th ed.. Homewood, IL: Irwin.

Lerner, A. P. 1933-1934a. The diagrammatical representation of elasticity of demand. Review of Economic Studies 1 (1): 39-44.

. 1933-1934b. The concept of arc elasticity of demand: II. Review of Economic Studies 1 (3): 229-30.

Machlup, F. 1952. The economics of seller's competition: Model analysis of seller's conduct. Baltimore: Johns Hopkins Press.

Seldon, J. R. 1986. A note on the teaching of arc elasticity. Journal of Economic Education 17 (2): 120-24. 
Copyright of Journal of Economic Education is the property of Heldref Publications. The copyright in an individual article may be maintained by the author in certain cases. Content may not be copied or emailed to multiple sites or posted to a listserv without the copyright holder's express written permission. However, users may print, download, or email articles for individual use. 